\title{
People and the state. an anthropology of planned development, par A.F. Robertson, Cambridge University Press, 1984.
}

\section{Marcel Djama}

\author{
(2) OpenEdition \\ Journals \\ Édition électronique \\ URL : http://journals.openedition.org/apad/311 \\ DOI : 10.4000/apad.311 \\ ISSN : 1950-6929 \\ Éditeur \\ LIT Verlag \\ Édition imprimée \\ Date de publication : 15 mars 1991 \\ Référence électronique \\ Marcel Djama, « People and the state. an anthropology of planned development, par A.F. Robertson, \\ Cambridge University Press, 1984. », Bulletin de l'APAD [En ligne], 1 | 1991, mis en ligne le 07 juin 2006, \\ consulté le 23 septembre 2020. URL : http://journals.openedition.org/apad/311 ; DOI : https://doi.org/ \\ 10.4000/apad.311
}

Ce document a été généré automatiquement le 23 septembre 2020.

Bulletin de I'APAD 


\title{
People and the state. an anthropology of planned development, par A.F. Robertson, Cambridge University Press, 1984.
}

\author{
Marcel Djama
}

1 L'ouvrage de A.F. Robertson peut être perçu comme un avatar de ces démarches régénératrices d'une anthropologie prétendue moribonde et pour laquelle la cure oscille entre la recherche de nouveaux champs d'étude et la "revisitation" d'objets anciens. L'auteur opte explicitement pour cette première approche puisqu'il se propose d'étudier le développement planifié dans une perspective anthropologique "comme un système symbolique $\mathrm{C}$.), un ensemble de catégories visant à manipuler les gens et les ressources dans l'espace et le temps" (p.87). L'ouvrage débute par un long chapitre dans lequel est exposée l'histoire des idées et des politiques de développement.

2 Dans le chapitre consacré aux organisations il présente les éléments d'une problématique qui appréhende les bureaucraties (instruments de l'application des politiques de développement) et les communautés locales (champs d'application des politiques) comme des arènes politiques, des lieux de compétition entre acteurs sociaux. L'apport le plus original de l'ouvrage est sûrement cette idée de la confrontation entre deux formes de planification : celle de l'État et celle du "peuple", comme nœud de la contradiction inhérente à l'implantation de projets. Il est regrettable que l'auteur n'investigue pas davantage les formes locales de planification notamment dans l'étude du cas malais qu'il présente. Malgré la faiblesse de cet aspect de la démonstration et le flou qui entoure parfois les conditions d'application de l'anthropologie au contexte de développement, le texte de A. F. Robertson est fondateur en ce qu'il explore de manière exhaustive et pertinente un domaine délaissé par l'académisme anthropologique. 